\title{
Preferences Toward Risk and Asset Prices: Evidence from Russian Lottery Bonds
}

\author{
Andrey D. Ukhov* \\ Kelley School of Business \\ Indiana University
}

03 November 2005

\begin{abstract}
This paper studies the relationship between investor risk preferences and asset returns. The paper provides direct evidence on the risk aversion of participants in a securities market. It uses the prices of lottery bonds issued by the Imperial Russian Government in 1864 and 1866 to estimate investor risk aversion and to study changes in preferences toward risk. Time variation in investor risk preferences is then compared to the dynamics of the Russian bond market over the period 1889 to 1904 . Increases in risk aversion are positively associated with increases in the price of a risk-free asset. This result is in accord with economic intuition that higher risk aversion is associated with higher demand for a safe asset, and hence, higher equilibrium price of a risk-free security and a lower risk-free rate. Implications of a Consumption CAPM model for a relationship between changes in interest rates and changes of risk aversion are tested. Evidence supporting the model is found. The paper provides evidence on the role of risk aversion in securities market dynamics.
\end{abstract}

JEL Classification: G1, D1, D8.

Keywords: Risk aversion, risk seeking, lottery pricing, investor sentiment.

${ }^{*}$ I thank Dan Bernhardt, David Brown, Markus K. Brunnermeier, Mikhail Chernov, Raj Chetty, Eric Hughson, Chris Leach, Mark Ready, Thomas Rietz, Robert Shiller, Jeremy Stein, Michael Stutzer, Charles A. Trzcinka, Arthur D. Warga, Jaime Zender, as well as seminar participants at the University of Iowa, and conference participants of the Yale School of Management Conference on the History of Financial Innovation, the 2005 ASSA Annual Meeting in Philadelphia, and the 2005 Western Finance Association Annual Meetings for helpful discussions and suggestions. I am especially grateful to William N. Goetzmann, Jonathan E. Ingersoll, Jr., Andrew Jeffrey, and Matthew Spiegel. Address correspondence to: Andrey D. Ukhov, Kelley School of Business, Indiana University, 1309 East Tenth Street, Bloomington, IN 47405, USA. Telephone: 812-855-2698 E-mail: aukhov@indiana.edu 


\title{
Preferences Toward Risk and Asset Prices: Evidence from Russian Lottery Bonds
}

\begin{abstract}
This paper studies the relationship between investor risk preferences and asset returns. The paper provides direct evidence on the risk aversion of participants in a securities market. It uses the prices of lottery bonds issued by the Imperial Russian Government in 1864 and 1866 to estimate investor risk aversion and to study changes in preferences toward risk. Time variation in investor risk preferences is then compared to the dynamics of the Russian bond market over the period 1889 to 1904. Increases in risk aversion are positively associated with increases in the price of a risk-free asset. This result is in accord with economic intuition that higher risk aversion is associated with higher demand for a safe asset, and hence, higher equilibrium price of a risk-free security and a lower risk-free rate. Implications of a Consumption CAPM model for a relationship between changes in interest rates and changes of risk aversion are tested. Evidence supporting the model is found. The paper provides evidence on the role of risk aversion in securities market dynamics.
\end{abstract}

JEL Classification: G1, D1, D81.

Keywords: Risk aversion, risk seeking, lottery pricing, investor sentiment. 


\section{Introduction}

Asset pricing theories postulate that asset returns reflect risk characteristics of an asset, as well as risk preferences of the investors. Preferences toward risk are captured by risk aversion - a fundamental concept in financial economics that dates back to the work of Bernoulli (1738). ${ }^{1}$ The degree of aversion to risk determines the amount of compensation required by investors for holding assets with uncertain payoffs and is related to the returns on risky assets and to the risk free rate. When preferences toward risk change, they cause asset prices to change. ${ }^{2}$

Many empirical papers have studied the relationship between asset risk and return, both crosssectionally and in time series. Less empirical work has been done on uncovering the nature of the relationship between investor risk preferences and asset returns. In practice, risk aversion is difficult to measure. The definition is based on a price an investor is willing to pay for a gamble with a known payoff distribution. Estimation of risk aversion therefore requires prices of gambles with known probabilities. Simple lotteries with known prize amounts and probabilities are not traded in any marketplace. A proxy correlated with risk preferences is also hard to construct.

Although the nature of the connection between risk aversion and asset prices is ultimately an empirical issue, the link has proven to be difficult to establish. Asset prices can be used together with a theoretical asset pricing model to obtain estimates of risk aversion. These estimates, however, cannot be used to test the model's predictions about the role that risk preferences play in determining asset prices because the estimates already depend on the specific model employed.

This paper uses market prices of lottery bonds to study the relation between risk preferences and asset prices. In addition to the regular coupon payments, lottery bonds distribute monetary

\footnotetext{
${ }^{1}$ Bernoulli (1738) believed that it is "...Nature's admonition to avoid the dice altogether..." and pointed out that an economic agent requires compensation for holding a fair gamble. For the classical treatment of risk aversion see Arrow (1964, 1965, 1970) and Pratt (1964).

${ }^{2}$ For example, Barberis, Huang, and Santos (2001) develop an asset pricing theory that in essence is based on changing risk preferences. In simulations, their framework can help explain the high mean, excess volatility, and predictability of stock returns.
} 
awards through lottery drawings. On certain dates a bond behaves as a freely-traded lottery ticket. The paper shows how the market value of participating in the lottery can be extracted from the market prices of the bonds. This value can be used to estimate the coefficient of risk aversion. The method does not rely on an asset pricing model and the estimates obtained reflect market risk preferences. Changes in the market value of the lottery capture changes in preferences toward risk. The paper then compares time variation in risk preferences to the behavior of interest rates. The main finding is that when preferences toward risk change, they cause prices of the risk-free asset to change. The result is consistent with the economic intuition that higher aversion to risk is associated with higher demand for the safe (risk-free) asset and hence a lower equilibrium risk-free rate. The results are robust to several econometric specifications and indicate a high signal-to-noise ratio present in the data.

Many authors have suggested clever, indirect empirical approaches to estimate risk aversion (see, for example, Grossman and Shiller 1982). Schilbred (1973) used the data from the Italian bond market to obtain an estimate of the market price of risk in a mean-variance equilibrium model. The bonds in his study were redeemed at random, via lottery drawings, and therefore had uncertain maturity. Schilbred (1973) reported the estimated market price of risk of $£ 0.5$ per unit of variance, but the study used variables in levels and may have suffered from econometric problems caused by non-stationary data.

In a more recent study, Brav, Constantinides and Geczy (2002) use household-level quarterly consumption data from the Consumer Expenditure Survey (CEX) produced by the Bureau of Labor Statistics (BLS) to calculate the relative risk aversion coefficient as the ratio of the sample mean of the equity premium and the covariance of consumption growth with the market index. Noisy consumption growth, however, creates estimation problems.

Jackwerth (2000) uses the methodology described in Aït-Sahalia and Lo (2000) to recover risk aversion from option prices and realized returns on the S\&P 500 index. He finds that risk aversion changes dramatically around the 1987 stock market crash. Before the crash, he finds evidence of aversion to risk - a finding consistent with standard assumptions made in economic theory. He reports robust findings, however, that after the crash many estimates of the risk aversion coefficient are negative, implying risk seeking.

Another approach to studying risk preferences is through surveys or controlled laboratory exper- 
iments (Guiso and Paiella 2001; Holt and Laury 2002; Kachelmeier and Shehata 1992). Guiso and Paiella (2001) use household survey data and measure absolute risk aversion based on the maximum price a consumer is willing to pay to enter a hypothetical lottery. For most survey respondents, self-reported values of the right to participate in a lottery are below the expected lottery value and therefore indicate aversion to risk. In the laboratory experiments of Holt and Laury (2002) approximately two-thirds of the subjects exhibit risk aversion. Kachelmeier and Shehata (1992), and Guiso and Paiella (2001) argue that offering large lotteries is a better way to characterize risk aversion of expected utility maximizers. Much can be learned about risk preferences from surveys and experiments. It is difficult, however, to address the issue of time variation in preferences toward risk because surveys and experiments would have to be conducted with some periodicity. The problem of establishing a link between risk aversion of decision makers and the outcomes of their behavior, such as asset prices or results of an auction, also remains to be studied in an experimental setting. Is it the case that peculiarities of individual preferences toward risk cancel out in equilibrium, or do they aggregate in such a way as to affect on asset prices? At present, experimental studies do not address these questions.

Recently, researchers have discovered that lottery bonds provide a unique opportunity to study risk preferences. For example, Green and Rydqvist (1997) use Swedish bonds, whose coupons are determined by lottery, to estimate the pricing of idiosyncratic risk. These bonds, issued by the Swedish Treasury, have a fixed total coupon payment on any given date, but the allocation of the payment across bonds within the issue is determined by lottery. The study concludes that diversifiable risk is priced.

Green and Rydqvist (1999) use Swedish lottery bonds to study the effects of differential tax rates on income and capital gains on ex-day price behavior. Florentsen and Rydqvist (2002) use the pricing of Danish lottery bonds to study tax-based explanations of abnormal ex-day returns. The Danish bonds in their study make coupon payments by lottery. They find evidence consistent with the costly arbitrage argument. Florentsen and Rydqvist (2002) also find that the variance of the coupon lottery influences the ex-day returns on the bonds. Ex-day returns increase with the variance of the coupon lottery suggesting that lottery risk affects security pricing and requires compensation.

Lottery bonds have a long history in financial markets, and have been issued in a number of 
different forms and structures. For example, the Danish government issued the first lottery bond in 1948 and, in Sweden, lottery bonds have been issued since 1918 (Green and Rydqvist 1997). In this paper, I collect market prices of Russian lottery bonds issued in the 1860's and use this dataset as the basis for estimating risk aversion. Lottery bonds represented two-thirds of debt issued by the Russian government, the largest borrower in the world at the time. These bonds differ significantly from those studied by previous authors in that they have embedded lottery rights and they have traded for long periods of time in the secondary market at observable prices. By observing the market prices of these bonds it is possible to compute prices paid to participate in lotteries. This creates a unique opportunity to observe market prices of lotteries with known payoff distribution and to study risk aversion in a non-experimental setting.

This paper shows how this data can be used to directly estimate an Arrow-Pratt measure of risk aversion for a representative participant in the lottery. In contrast with survey based studies that report aversion towards lotteries, I find evidence of risk seeking behavior. A risk aversion index based on lottery bond prices is also estimated. The time variation in the index is a proxy for changes in market risk preferences. The time variation in preferences toward risk is then compared to the dynamics of the Russian bond market over the period 1889 to 1904. I find evidence of a positive relationship between changes in risk aversion and changes in prices of risk-free bonds. This result is in accord with economic intuition that higher risk aversion is associated with higher demand for a safe asset and hence higher equilibrium bond prices. I also test the implications of a Consumption CAPM model with heterogeneous income risk for a relationship between changes in the risk free rates and changes in the level of risk aversion. I find evidence supporting the model. In addition, Granger (1969) causality tests indicate that changes in investor risk preferences cause changes in the interest rate. The paper thus provides some evidence on the role of risk aversion in security market dynamics. The intertemporal fluctuation in risk preferences is consistent with behavioral models and empirical evidence suggesting that investor sentiment fluctuates.

This paper is structured as follows. The next section describes Russian lottery bonds. Section 3 develops the method used for estimating the Arrow-Pratt measure of absolute risk aversion from lottery prices. Section 4 reports the results and Section 5 concludes. 


\section{Historical Background and Description of Lottery Bonds}

\subsection{The Reforms of Alexander II}

Lottery bonds were issued by the Russian government during the time of political and economic reforms of Tsar Alexander II in the years following the Crimean War (1853-1856). Alexander II abolished the system of peasant slavery in 1861, liberalized foreign trade and foreign investment regulations, and eliminated many restrictions on private economic activities. The reforms stimulated the development of private enterprise and fueled the growth of the Russian capital market. The securities market was virtually non-existent in 1856 when only six public companies, with total capital of 15.5 million rubles, were registered. By 1858 the market capitalization tripled, and by 1865, the Russian Finance Ministry was collecting and publishing detailed price and capitalization information about its public securities markets. ${ }^{3}$

Securities issued by new public companies competed with state bonds and government-run banks because they offered or promised higher rates of return. The demand for capital was high and the government lifted the ban on private borrowing from abroad - prior to mid 1850's, foreign capital could enter Russia only through state foreign loans. Thus, the "curtain" established by Tsar Nicholas I out of fear of foreign democratic ideas was lifted due to the pressure of the expanding economy. The prestige of the Russian government suffered serious damage after the loss of the Crimean War and the State found it difficult to obtain loans abroad. Competitive capital markets, freed by the liberal economic policy, forced the government to look for innovative solutions to finance the budget deficit. The Russian government introduced newly designed lottery bonds as it looked for ways to increase investor participation, to attract new investors into the market, and to induce savers to shift from holding precious metals and commodities into government debt instruments. This also helped the development of the Russian capital market by increasing the number of domestic investors.

\footnotetext{
${ }^{3}$ See Vagner (1871) or Ukhov (2002). Although Russia was a major borrower on the world capital markets, Russian government debt was regarded as one of the safe assets. The Russian government has never missed a payment due prior to the 1917 Revolution. Our study covers a 16-year period between 1889 and 1905. A careful examination of the premier British financial publication, The Investors Monthly Manual, reveals that there were never any speculations about default. The Russian Finance Ministry valued its reputation of a safe borrower and safeguarded it.
} 


\subsection{Description of Russian Lottery Bonds}

The Russian Imperial Government issued lottery bonds for the first time in November of 1864 under the official title of "Internal 5\% Lottery Bonds." To attract small investors the bonds were issued as bearer securities with a relatively small face value of 100 rubles per bond. The total value of the issue was 100 million rubles - one million individual securities were placed.

The bonds did not have a fixed maturity date. They were called at random and retired by the government within 60 years from the issue date. Each bond had a serial number and an individual number. Twice a year a recall drawing for serial numbers took place. The owner of a recalled bond received the face value of the bond plus a recall premium. The premium was set at 20 rubles per bond for the first series of recalls and gradually increased to 50 rubles for the bonds recalled in the later years. These were $5 \%$ bonds with semiannual coupons of 2.50 rubles each paid on January 2nd and July 1st.

The bonds had an innovative feature - a lottery that gave the owner a chance to win cash prizes. According to the lottery schedule printed on the back of every bond certificate, prize drawings took place twice a year (January 2 and July 1) for the first 30 years and once a year (January 2) during the last 30 years. Random lottery drawings were conducted by the Board of the State Bank immediately prior to the recall drawings. Small pieces of cardboard with the individual number and serial number of each outstanding bond were placed in large rotating drums. The members of the Board blindly picked these pieces of cardboard to determine the winning bonds. Recall drawings were conducted in the same fashion, except only serial numbers were drawn. All terms of the issue, including the provisions for calling the bonds and the amounts of monetary prizes, were printed on the back of the bond certificate in two languages: Russian and German. Bondholders had the certificate in their possession and knew the terms of the contract. Investors paid no taxes on income from capital gains, lottery winnings, or interest payments during the period studied.

At each lottery drawing, 300 prizes, totalling 600,000 rubles, were awarded. At each drawing a bond could win only once. The prizes are listed in Table 1. The smallest prize was 500 rubles which was approximately equal to three months income of a civil servant in the 1880s. In 1903 a Lieutenant General, a high military ranking officer, made 500 rubles a month. The highest prize equalled 200,000 rubles, the General's income over 33 years. The winner received the payment of the prize three months after the drawing date. The bond was stamped to record the payment. The 


\begin{tabular}{ll}
\hline \hline & Table $\mathbf{1}$ \\
Prizes Awarded at Each Lottery Drawing \\
\hline Prize Value, $Z_{k}$ & Number of Prizes \\
200,000 rubles & 1 prize \\
75,000 rubles & 1 prize \\
40,000 rubles & 1 prize \\
25,000 rubles & 1 prize \\
10,000 rubles & 3 prizes \\
8,000 rubles & 5 prizes \\
5,000 rubles & 8 prizes \\
1,000 rubles & 20 prizes \\
500 rubles & 260 prizes \\
\hline \hline
\end{tabular}

bond could participate in all drawings until it was recalled, so, in theory, the owner had a chance to win on several dates. A lottery bond, therefore, was effectively a regular government coupon bond with many lottery tickets "attached" that gave the holder the right to participate in many lottery drawings.

At the time of placement, the 1864 issue of lottery bonds was moderately successful. It was placed at 98.6 rubles per 100 ruble face-value bond. Later, the interest in lottery bonds was fueled by the news of large winnings. The government decided to capitalize on the popularity of the lottery bonds, and, in 1866, it placed the issue of the "Second Internal 5\% Lottery Bonds." The summary of features of the 1866 bonds is presented in the Appendix. The total value of this issue was also 100 million rubles. All the features of the second issue were identical to the features of the 1864 issue with the exception that the drawings and coupon payments took place on March 1st and September 1st, instead of in July and January. The issue of 1866 was more popular and was placed at 107 rubles per bond.

In 1870, the total value of Russian government debt, including paper currency and railway bonds, was 300 million rubles. Lottery bonds accounted for 200 million rubles, or two-thirds of the total value of debt. By 1889, total government debt increased to 563 million rubles and some lottery bonds were retired according to the recall schedule. Still, lottery bonds accounted for one-third of 
the debt of the largest debtor nation in the world.

\subsection{Public Perception}

According to some observers, lottery bonds were by far the most popular form of government debt. In 1870, the Russian population was 86 million. Two million lottery bonds were placed; one bond per 43 citizens. The market price of the bonds at times reached 1,000 rubles for a 100 ruble bond. This demand was fueled by the popular belief that "the chance of winning a prize increased as the total number of outstanding bonds declined with recalls." Since the bonds traded at a premium the owner faced the risk of recall. The recall premium payment of 20 to 50 rubles could not compensate the bondholder for the loss of the market value. A financial innovation appeared - banks offered insurance for the event of recall. There was another innovation. Banks purchased lottery bonds and sold lottery participation rights. These securities gave the right to a specified percentage of the prize won in one drawing only. They were sold to those who could not afford to buy the bond but wanted to participate in one lottery.

Lottery bonds had clearly become a part of Russian popular culture. A Russian civil servant earned between 1,200 and 2,000 rubles a year in the 1880s and supported a family with a middle class life-style on that amount. A lottery bond that had a chance to win 75,000 or even 200,000 rubles was an exciting security and perhaps even a source of hope. The time of drawings was the time of anticipation. Anton Chehov, the great writer and an acute chronicler of middle class Russian life, wrote a number of stories in which these bonds played a part. In the short story "75,000" published in January 1884, he describes the happiness in a family when a young wife finds out that her bond has won 75,000 rubles and the deep sorrow when she discovers that the bond has been stolen and she can no longer claim the prize. ${ }^{4}$ In the play "The Wedding: A Scene in One Act," written in October 1889, lottery bonds are an important part of the bridal gift (dowry).

In spite of their success, or maybe precisely because of it, lottery bonds attracted criticism. In an interesting parallel to the media outcry during the recent U.S. Dot Com mania, the critics said that the bonds fed interest in public "get rich quick" schemes instead of building strong ethics of prudence and saving. Curiously, contemporary critics complained that the bonds were an expensive

\footnotetext{
${ }^{4}$ The other short stories are: "The Winning Ticket" (March 9, 1887) and "Everyday Troubles," (March 28, 1887). The last story mentions insurance against recall.
} 
way to raise capital because large amount of money had to be paid in prizes as well as in recall payments. They, of course, ignored the premium paid for the lottery payoff. ${ }^{5}$

\section{Calculating Risk Aversion from Lottery Prices}

The method for estimating the Arrow-Pratt measure of absolute risk aversion from lottery prices is developed in this section. Let $U(W)$ be a twice continuously differentiable utility of wealth function. The Arrow-Pratt absolute risk aversion is defined as $R_{A}(W) \equiv-U^{\prime \prime}(W) / U^{\prime}(W)$. Relative risk aversion is defined as $R_{R}(W) \equiv W R_{A}(W)$.

Consider a lottery with $K$ prizes $\left\{Z_{k}\right\}_{k=1}^{K}$ paid with probabilities $\left\{\alpha_{k}\right\}_{k=1}^{K}$. The lottery pays zero with probability $\left(1-\sum_{k=1}^{K} \alpha_{k}\right)$. Let $\lambda$ be the price that a risk averse investor is willing to pay to participate in the lottery. Then $\lambda$ (lottery participation fee) is such that the investor is indifferent between holding $W$ and taking the gamble,

$$
\begin{aligned}
U(W) & =\mathbb{E} U(W+\widetilde{Z}-\lambda) \\
U(W) & =\left(1-\sum_{k=1}^{K} \alpha_{k}\right) U(W-\lambda)+\sum_{k=1}^{K} \alpha_{k} U\left(W+Z_{k}-\lambda\right) .
\end{aligned}
$$

Following Pratt (1964), I use a Taylor series approximation to obtain

$$
\begin{aligned}
U(W)= & \left(1-\sum_{k=1}^{K} \alpha_{k}\right)\left[U(W)-U^{\prime}(W) \lambda+\frac{1}{2} U^{\prime \prime}(W) \lambda^{2}\right] \\
& +\sum_{k=1}^{K} \alpha_{k}\left[U(W)+U^{\prime}(W)\left(Z_{k}-\lambda\right)+\frac{1}{2} U^{\prime \prime}(W)\left(Z_{k}-\lambda\right)^{2}\right] .
\end{aligned}
$$

Rearranging (3.1) and using the definition of risk aversion,

$$
R_{A}(W)=-\frac{U^{\prime \prime}(W)}{U^{\prime}(W)} \approx \widehat{a}=\frac{\sum_{k=1}^{K} \alpha_{k} Z_{k}-\lambda}{\frac{1}{2} \lambda^{2}+\frac{1}{2} \sum_{k=1}^{K} \alpha_{k} Z_{k}^{2}-\lambda \sum_{k=1}^{K} \alpha_{k} Z_{k}} .
$$

\footnotetext{
${ }^{5}$ Tarankov (1992) reports that cost of capital was estimated by Russian officials to be $6.34 \%$. Consistent with Florentsen and Rydqvist (2002), I find that the lottery feature may indeed have raised, rather than lowered the cost of capital. The estimate for the cost of capital computed based on the bond pricing developed in this paper equals $6.571 \%$. Absent the lottery feature the cost of capital by our calculation falls to $5.365 \%$. Thus, lottery prizes in effect contributed a significant amount to the cost of debt. Cost of capital is computed as the yield to maturity that sets the bond price at issue to par value of 100.00. Calculation were carried out as if there was no cancellation of bonds by the Soviet government, an event not anticipated in the late 19th century.
} 
The value of the lottery prizes, $Z_{k}$, in (3.2) are known from the bond certificates. I show next how to calculate the probabilities $\alpha_{k}$ of winning the prizes and the expected value of the lottery winnings. I will also show how to use market prices of lottery bonds to compute the market lottery value $\lambda$.

\subsection{Expected Lottery Value}

Lottery winnings were based on draws without replacement for 300 prizes from the pool of all outstanding bonds. Each bond was equally likely to be selected for each of the prizes. The probability of winning prize $k$ was the same for all prizes. The expected value (without discounting) of the lottery drawing number $j, \mathbb{E}[\operatorname{Lottery}(j)]$, is given by

$$
\mathbb{E}[\operatorname{Lottery}(j)]=\frac{1}{O_{j}} \sum_{k=1}^{300} Z_{k}, \quad \alpha_{k}=\frac{1}{O_{j}} \text { for all } k,
$$

where $O_{j}$ is the number of bonds outstanding at the time of drawing $j$.

Let $D(t, j)$ be the discount factor used to obtain the present value at time $t$ of a payment that is made at time $j$. The notation $D(t, j+3 m)$ means that the winnings of the lottery number $j$ were actually paid three months after the drawing date. Then $L(t, i)$, the expected present value at time $t$ of all lottery winnings between time $t$ and time $i$, equals

$$
L(t, i)=\sum_{j=i_{1}}^{i} D(t, j+3 m) \cdot \mathbb{E}[\operatorname{Lottery}(j)],
$$

where $i_{1}$ is the first drawing at or after time $t$.

\subsection{Participation Fee and Bond Prices}

Investors pay to participate in the lottery. For example, an investor could purchase a bond before a drawing date and sell the bond afterwards. This transaction is equivalent to purchasing a right to participate in the lottery drawing. The value of the right to participate, $\lambda$, can be determined from the market prices of the bonds before and after a drawing date.

Let $i^{-}$and $i^{+}$denote a date before and a date after the lottery drawing $i$, respectively. Assume that there is exactly one lottery drawing $i$ between times $i^{-}$and $i^{+}$. Let $P\left(i^{-}\right)$and $P\left(i^{+}\right)$be the observed market prices of the bonds at $i^{-}$and $i^{+}$. Use $\lambda_{i}$ to denote the value of the right to 
participate in the lottery $i$. Write $C(t, i)$ for the present value at $t$ of all coupons received between $t$ and $i$, and $F(t, i)$ for the present value at $t$ of the recall payment paid if recalled at $i$.

The bond price before a drawing date, $P\left(i^{-}\right)$, is the price of (a) the claim to all coupon payments between $i^{-}$and $i$, including the coupon payable at $i,(\mathrm{~b})$ the right to participate in the lottery drawing $i,(\mathrm{c})$ the right to receive the recall payment if the bond is recalled at $i$, and (d) the right to keep the bond if the bond is not recalled. Hence, bond price equals the sum of the prices of these four components as follows:

$$
P\left(i^{-}\right)=C\left(i^{-}, i\right)+\lambda_{i}+\mu_{i^{-}}^{i} \cdot F\left(i^{-}, i\right)+\left(1-\mu_{i^{-}}^{i}\right) \cdot P\left(i^{+}\right)
$$

where $\mu_{i^{-}}^{i}=\mathbb{P}\left\{\right.$ Recall on drawing $i \mid$ Outstanding at $\left.i^{-}\right\}$. The right to participate in the $i$-th drawing is related to the bond prices via

$$
\lambda_{i}=P\left(i^{-}\right)-C\left(i^{-}, i\right)-\mu_{i^{-}}^{i} \cdot F\left(i^{-}, i\right)-\left(1-\mu_{i^{-}}^{i}\right) \cdot P\left(i^{+}\right) .
$$

The probability of recall, $\mu_{i^{-}}^{i}$, is computed from the number of bonds outstanding at the time of the $i$-th drawing, $O_{i}$,

$$
\mu_{i^{-}}^{i}=n_{i} / O_{i}
$$

where $n_{i}$ is the total number of bonds recalled at $i$. Both $n_{i}$ and $O_{i}$ are known for any date from the contract specification. It remains to provide formulae for $C(t, i)$ and $F(t, i)$.

\subsection{Coupon Payments and Recall Payment}

Next, I derive the expressions for $C(t, i)$ and $F(t, i)$. As before, let $i_{1}$ denote the first drawing at or after time $t$. Coupons of 2.50 rubles were paid semiannually on the days of the drawings, beginning from the first drawing (1 July 1865 for the 1864 lottery bonds and 1 September 1866 for the 1866 lottery bonds). There is one special case. For the bonds recalled on the first drawing two coupons were paid - the one due at the time of the drawing and the coupon due six months afterwards. The second coupon was paid three months after the drawing when the bond was recalled and not on its actual due date. The indicator function $\mathbf{1}\{i=1\}$ is used to account for this special case,

$$
\mathbf{1}\{i=1\}= \begin{cases}1 & \text { if } i=1 \\ 0 & \text { if } i \neq 1\end{cases}
$$


Using the indicator function, the expression for $C(t, i)$ is:

$$
C(t, i)=\left(\sum_{j=i_{1}}^{i} D(t, j) \cdot 2.50\right)+\mathbf{1}\{i=1\} \cdot D(t, i+3 m) \cdot 2.50
$$

The amount paid to the owner when a bond was recalled varied from 120 to 150 rubles depending on the date of recall. The payment was made three months after the bond had been drawn for recall. Using the table printed on the bond certificate:

$$
F(t, i)=D(t, i+3 m) \cdot \begin{cases}120 & \text { if } 1 \leq i \leq 20 \\ 125 & \text { if } 21 \leq i \leq 50 \\ 130 & \text { if } 51 \leq i \leq 70 \\ 135 & \text { if } 71 \leq i \leq 90 \\ 140 & \text { if } 91 \leq i \leq 100 \\ 145 & \text { if } 101 \leq i \leq 112 \\ 150 & \text { if } 113 \leq i \leq 120\end{cases}
$$

\subsection{Pricing Lottery Bonds}

The methodology of pricing 1864 and 1866 lottery bonds is identical since both issues had identical terms. Here, the formula for pricing 1866 lottery bonds is derived; the formula for the 1864 issue is identical except for the specific calendar dates of issue, coupon payments, and drawings. The calendar dates for which the formulae are valid are also different for the 1864 and 1866 bonds - it is meaningless to speak of pricing 1866 bonds on January 1, 1865 when they were not yet issued.

Let $P_{t}^{*}$ denote the theoretical price of the lottery bond at time $t$ (not the observed market value). The 120 drawings were held on March 1 and September 1 of each year beginning on September 1, 1866. Each of the drawings are indexed by $i \in\{1,2, \ldots, 120\}$. According to the original schedule printed on every bond, two separate and independent drawings took place for each of the first 60 drawings: a prize drawing was conducted first to determine lottery winners and a cancellation (or recall) drawing took place immediately after the prize drawing. According to the schedule, lottery drawings took place twice a year during the first 30 years and once per year during the last 30 years. Beginning with drawing number 61 (September 1, 1896), the September drawings included only recall drawings. Prize drawings were no longer conducted in September. Without loss of generality, 
I treat all drawings as if they included both the prize drawing and the cancellation drawing. The values of all prizes are set to zero for drawings $\{61,63,65, \ldots, 117,119\}$.

I now derive the expression for the price of a lottery bond, $P_{t}^{*}$. Time $t$ is such that there is at least one drawing that has not yet occurred. If time $t$ is the date of a drawing, I assume that the price $P_{t}^{*}$ is calculated before any drawings have taken place. Since coupon payments and drawings take place on the same date, I assume that the coupon has not yet been paid and $P_{t}^{*}$ includes the coupon payment at $t$.

If the bond is recalled at drawing $i$, then its value consists of $C(t, i)$, the present value of all coupons received between time $t$ and time $i, L(t, i)$, the expected present value of all lottery winnings between time $t$ and time $i$, and $F(t, i)$, the present value of the principal payment. The price of the bond at time $t$ is then given by

$$
P_{t}^{*}=\sum_{i=1}^{120} \mathbb{P}\{\text { Recall on drawing } i \mid \text { Outstanding at } t\} \cdot[C(t, i)+L(t, i)+F(t, i)]
$$

As before, I use $\mu_{t}^{i}$ to denote the probability of recall during the recall drawing $i$ given that the bond is still outstanding at $t$. Thus, for all drawings scheduled on a date before $t, \mu_{t}^{i}=0$. It is shown in Appendix B that

$$
\mu_{t}^{i}= \begin{cases}0 & \text { if drawing } i \text { takes place before time } t \\ \frac{n_{i_{1}}}{O_{i_{1}}} & \text { for the first drawing after } t: i=i_{1} \\ \frac{n_{i}}{O_{i}} \cdot \prod_{j=i_{1}}^{i-1}\left[1-\frac{n_{j}}{O_{j}}\right] & \text { for all other } i\end{cases}
$$

The formulae for $C(t, i)$ and $F(t, i)$ in the decomposition (3.4) were established earlier. We now have explicit expressions for the bond price $P_{t}^{*}$.

\section{Empirical Study}

\subsection{Data}

The data for this study consists of prices of the 1864 and 1866 lottery bonds. The prices were manually retrieved from various issues of the newspaper Novosti i Birzhevaya Gazeta. Two prices are collected for each lottery date from January 1889 to January 1905 - a 16-year period. ${ }^{6}$ The

\footnotetext{
${ }^{6}$ A note on the calendars and dates. The Russian Empire used the Julian calendar. It differs from the Gregorian calendar, used in the West at the time and throughout most of the world now. The Julian calendar specifies that
} 
first is the price on a trading date before the lottery drawing date. The second is the ex-lottery price, which is a market price on a trading date after the lottery. There are 3 missing observations due to incomplete records leaving us with 42 data points. ${ }^{7}$ This study also uses the yields on the $5 \%$ Russian Government perpetuity of $1822, Y_{t}$, as the interest rate. ${ }^{8}$

A few additional assumptions are required. First, for purposes of avoiding the estimation of a full bond pricing model, a flat yield curve is assumed. Second, I assume the probability of default by the government is zero. We know, of course, that these bonds eventually defaulted. However, I argue that expectations of such an event were minimal for much of the period of interest. Also, I use the change in bond prices around the lottery drawing date to estimate risk aversion. If bond prices before and after the lottery date both contain the same default information, then we do not need to account for default probability.

For each drawing date $t$, equation (3.3) is used to compute the value of the lottery participation right, $\lambda_{t}$, from the bond prices. Then, equation (3.2) is used to obtain the estimate of the Arrow Pratt measure of risk aversion at time $t, \widehat{a}_{t}$. This procedure produces a time series of the estimated risk aversion coefficient.

The first result is that out of 42 estimates only one is above zero indicating risk averse behavior. All the other estimates of the Arrow-Pratt measure of risk aversion are negative which is consistent with risk seeking behavior. This is in sharp contrast with most studies based on surveys where the authors find self-reported risk aversion towards lottery tickets. Table 2 shows the summary statistics for the estimated risk aversion coefficient.

every year that is a multiple of 4 is a leap year. The Gregorian calendar excludes leap years in century years not divisible by 400. So, for example 1900 was not a leap year, although 2000 was. At the time the Julian calendar was 11 days behind the Gregorian calendar. Russia converted from the Julian calendar to the Gregorian calendar in 1918 - February 1, 1918 was followed by February 14, 1918.

${ }^{7}$ For the 1864 bond there are two missing observations during the period; one that corresponds to the July 1 , 1890 lottery and the other that corresponds to the January 2, 1895 lottery drawing. For the 1866 bond there is one missing observation that corresponds to the March 1, 1898 drawing.

${ }^{8}$ I thank William N. Goetzmann for sharing bond yield data. 


\begin{tabular}{cc}
\hline \hline Table 2 \\
Risk Aversion Estimate Summary Statistics \\
\hline Mean & -0.00010 \\
Median & -0.00008 \\
StDev & 0.00006 \\
Minimum & -0.00027 \\
Maximum & $2.50 \times 10^{-6}$ \\
\hline
\end{tabular}

For comparison, Guiso and Paiella (2001) find that in their survey, 96 percent of participants are risk averse and 4 percent are either risk neutral (3.6\% of the sample) or risk loving $(0.04 \%$ of the sample). The average absolute risk aversion coefficient among risk neutral and risk seeking individuals in their sample is, $\widehat{a}=-0.005$. Evidence of risk seeking is found by Jackwerth (2000) who reports that risk aversion as a function of wealth changes dramatically around the 1987 stock market crash. After the crash, risk aversion is found to be negative for a wide range of wealth values.

Since the estimated coefficient of risk aversion is negative in the sample (with exception of one value), for the remainder of the paper I will use the risk seeking coefficient defined as the negative of the estimated risk aversion coefficient,

$$
R S_{t}=-\widehat{a}_{t}
$$

A positive value of the risk seeking coefficient means risk seeking, and a negative value means risk aversion.

Figure 1 is a time series plot of the risk seeking coefficient $R S_{t}$ estimated from the change in prices of 1864 bonds and 1866 bonds. Estimation errors are reflected on the plot as differences in values of the coefficients obtained from the two bond issues when observations are close in time. Still, both series are close in value. This is as expected since the estimates are obtained from price changes of two bonds that are very close substitutes to each other. It is interesting to note that the peak of risk seeking in March of 1899 corresponds to a high level of stock prices on the St. Petersburg Stock Exchange. 
Each estimate of the risk aversion coefficient is based on $\lambda_{t}$, the value investors placed on the right to participate in the lottery. This value is computed from the price change on the lottery date. Hence, two prices around each lottery date are required to compute each risk aversion estimate. The number and frequency of observations in the risk aversion series thus depend on the number and frequency of lottery drawing dates. This limitation on the number of observations will affect the power of tests that use this data. The power to detect relationships will be further affected by the estimation errors. It is shown next how levels of prices can be used to construct a proxy for risk aversion, increasing the number of observations and power of the tests.

\subsection{Risk Attitude Index}

So far, I have it was discussed how changes in market prices of lottery bonds around the lottery date can be used to determine investor risk aversion. Market prices of lottery bonds on any trading date, however, also contain information on attitudes toward risk. The market price of a lottery bond reflects the value of all coupons and principal repayment plus the market value of all future lotteries. The value of future lotteries contains information on risk preferences. To extract such information we can compare the market price of lotteries to their expected value.

I now develop this approach more formally. Lottery bond pricing equation (3.4) can be written to highlight the fact that bond prices consist of two components: (a) the value of all coupons and expected recall premium, and (b) the value of all future lotteries. Thus,

$$
\begin{aligned}
P_{t}^{*}= & \sum_{i=1}^{120} \mathbb{P}\{\text { Recall on drawing } i \mid \text { Outstanding at } t\} \cdot[C(t, i)+L(t, i)+F(t, i)] \\
= & \sum_{i=1}^{120} \mathbb{P}\{\text { Recall on drawing } i \mid \text { Outstanding at } t\} \cdot[C(t, i)+F(t, i)] \\
& +\sum_{i=1}^{120} \mathbb{P}\{\text { Recall on drawing } i \mid \text { Outstanding at } t\} \cdot L(t, i) .
\end{aligned}
$$

The first sum is the value of the bond absent the lottery feature. The second sum is the fair value of all future lotteries. The market price of all future lottery winnings, $\mathbb{M}_{t}$ [Lotteries], equals the market price of the bond minus the fair value of all coupons and recall payments,

$$
\mathbb{M}_{t}[\text { Lotteries }]=P(t)-\sum_{i=1}^{120} \mathbb{P}\{\text { Recall on drawing } i \mid \text { Outstanding at } t\}[C(t, i)+F(t, i)] \text {. }
$$


$\mathbb{M}_{t}$ [Lotteries] can be computed given the bond market price. The expected value at time $t$ of future lotteries is given by the sum

$$
\mathbb{E}_{t}[\text { Lotteries }]=\sum_{i=1}^{120} \mathbb{P}\{\text { Recall on drawing } i \mid \text { Outstanding at } t\} \cdot L(t, i)
$$

which can be computed for any date $t$. Define the Risk Seeking Index at time $t$ as the ratio of the market value of the future lotteries to the fair value of the lotteries,

$$
R S I_{t}=\frac{\mathbb{M}_{t}[\text { Lotteries }]}{\mathbb{E}_{t}[\text { Lotteries }]}-1
$$

The index value equals 0 when investors pay exactly the expected value of future lotteries - the market price of lotteries equals their expected value. This corresponds to the case of risk-neutrality. A value of the index below 0 corresponds to risk aversion, since the market value of the lotteries is less than their expected value. Finally, the index above 0 indicates risk seeking behavior. For example, value of $R S I_{t}=1$ means that investors were willing to pay twice as much as the expected value of all future lottery winnings.

I use 99 monthly observations of market prices of the 1866 lottery bond to compute the index time series, $R S I_{t}$. Discount rates are the yields on the $5 \%$ Russian Government perpetuity of 1822 . Figure 2 is a plot of the $R S I$ and the time series of the estimated risk seeking coefficient. Both series move together (the correlation coefficient equals 0.67, significant at 1\%). From late 1897 until 1900 the risk seeking coefficient estimated from changes in bond prices on lottery dates diverges from the risk seeking index based on the bond price levels. The index displays less volatility during this period than the estimated risk seeking coefficient. After 1900, however, the RSI index becomes more volatile than the estimated risk seeking coefficient.

The RSI Index value starts at 7 in 1889 and quickly falls to 5 where it stays until June 1895 . It then begins to grow, at what appears to be an exponential rate until it reaches the maximum of 16.5 at the end of January 1902. Then, there is a rapid decline in the risk seeking index, followed by growth. Index summary statistics are presented in the Table 3 . 


\begin{tabular}{cc}
\hline \hline Table 3 \\
Risk Seeking Index Summary Statistics \\
\hline \\
Mean & 7.328 \\
Median & 6.253 \\
StDev & 3.310 \\
Minimum & 4.258 \\
Maximum & 16.497 \\
& \\
\hline \hline
\end{tabular}

These numbers indicate that, on average, investors were willing to pay 8 times the expected value of winnings to participate in the lottery. Often this number is above 10, and not once is there any evidence of risk aversion.

Having constructed a measure of risk attitude, I proceed to develop testable hypotheses about the relationship between interest rates and risk preferences.

\subsection{Risk Aversion and Bond Yields: Theory}

The theoretical relationship between risk aversion and the interest rate has been studied in many asset pricing models. In a standard single-period CAPM (Sharpe 1964, Lintner 1965, Mossin 1966, Lintner 1970, Friend and Blume 1975), an increase in risk aversion leads to an increase in precautionary savings demand and, therefore, to a decrease in the equilibrium interest rate. In general, the relationship is of the form:

$$
Y=K_{1}-K_{2} \cdot a,
$$

where $Y$ is the yield, $a$ is the risk aversion coefficient, and $K_{1}$ and $K_{2}>0$ are constants that describe the expected returns and variances of the investment opportunity set.

Research by Merton (1973), Lucas (1978), Breeden (1979, 1986), and Grossman and Shiller (1982) provides the theoretical foundation for a class of multiperiod consumption-based capital asset pricing models. In a model formulation that assumes no agent-specific endowment shock, a power utility of consumption, and a lognormal joint distribution of consumption and returns (see, 
for example Hansen and Singleton 1983), the general relationship between the interest rate and risk aversion coefficient takes the following form:

$$
\ln R=K_{1}-K_{2} \cdot \gamma
$$

Here, $R=1+Y, \gamma>0$ is the coefficient of relative risk aversion, the $K_{1}$ constant is the negative of the natural logarithm of the intertemporal discount factor, and the constant $K_{2}$ is the expected consumption growth rate, $K_{2}=\mathbb{E}_{t}\left[\ln \left(\widetilde{c}_{t+1} / c_{t}\right)\right]$. Since positive consumption growth is usually assumed, $K_{2}>0$. This relationship has a clear economic intuition. One would expect a higher level of risk aversion to be associated with a lower equilibrium risk free interest rate. High risk aversion implies high precautionary savings motive, high demand for the bond, and a high ratio of wealth invested in the bond to the wealth invested in risky securities. Thus, a high level of risk aversion results in a high bond price and, hence, a low yield. The negative relationship between the log-interest rate and risk aversion is equivalent to a positive relationship between the interest rate and risk seeking.

Hypothesis I: There is a negative relationship between interest rate and risk aversion.

In a Consumption CAPM where some income comes from sources other than the holdings of risky assets, such as an agent-specific labor income (Breeden 1986, Mankiw and Zeldes 1991, and more recently Barberis and Huang 2001), the relationship between risk aversion and interest rate generally takes the form:

$$
\begin{aligned}
\ln R & =K_{1}+K_{2} \cdot \gamma-K_{3} \cdot \gamma^{2} \\
K_{1} & \equiv-\ln \delta, \quad K_{2} \equiv \mu_{\ln C}=\mathbb{E}_{t}\left[\ln \left(\widetilde{c}_{t+1} / c_{t}\right)\right], \quad K_{3} \equiv \frac{1}{2} \sigma_{\ln C}^{2}
\end{aligned}
$$

where $K_{1}$ is the negative of the natural logarithm of the intertemporal discount factor $\delta<1, K_{2}$ is the expected consumption growth rate, and $K_{3}$ is a measure of the aggregate uncertainty in the economy over consumption (the variance of consumption growth). Testable implications follow from (4.1) by noting that $K_{3}$ is the variance of consumption growth and is therefore positive. To test the hypothesis $K_{3}>0$, note that our measure of risk seeking is a negative of risk aversion, $R S_{t}=-\widehat{\gamma}_{t}$ so that an increase in risk seeking corresponds to a decrease in risk aversion, $\Delta R S_{t}=-\Delta \widehat{\gamma}_{t}$, where $\Delta$ is the first difference operator. To estimate the model, I write (4.1) as a linear regression in first 
differences and levels,

$$
\begin{aligned}
\Delta \ln R_{t} & =\beta_{2} \cdot \Delta R S_{t}+\beta_{3} \cdot R S_{t-1} \cdot \Delta R S_{t}+v_{t}, \\
\beta_{2} & =-K_{1}, \quad \beta_{3}=-K_{3}<0 .
\end{aligned}
$$

Then, Hypothesis II is: $\beta_{3}<0$.

The linear relationship can be estimated using the time series of the interest rate and the time series of a proxy for risk preferences. Not only can the hypothesis $\beta_{3}<0$ be tested, but statistical significance of the coefficients and the sign of $\beta_{2}$ can be investigated empirically.

In a Consumption CAPM with power utility (see Lucas 1978, or Brav, Constantinides, and Geczy 2002 for a recent discussion), the change in yield, $\Delta Y$, is related to the change in the coefficient of relative risk aversion, $\Delta \gamma$, as follows:

$$
\frac{\Delta Y}{1+Y}=K \Delta \gamma
$$

where $Y=R-1$, and $K$ is defined as,

$$
K \equiv \mathbb{E}_{t}\left[\left(\frac{\widetilde{c}_{t+1}}{c_{t}}\right)^{-\gamma} \ln \left(\frac{\widetilde{c}_{t+1}}{c_{t}}\right)\right] / \mathbb{E}_{t}\left[\left(\frac{\widetilde{c}_{t+1}}{c_{t}}\right)^{-\gamma}\right] .
$$

It is assumed in the model that consumption, $\widetilde{c}_{t+1}$, has a log-normal distribution. Expected consumption growth rate, $\mathbb{E}\left[\left(\widetilde{c}_{t+1} / c_{t}\right)^{-\gamma}\right]$, is positive, and the sign of $K$ is determined by the sign of the numerator. The numerator is the expected value of a log-normal random variable multiplied by a normal random variable. The sign of this expected value depends on the mean and variance of the distribution of terminal consumption, $\widetilde{c}_{t+1}$. The numerator is positive for sufficiently high values of the mean and the numerator is negative for low values of the mean. The sign of the numerator depends also on the variance of terminal consumption. The numerator is negative for high values of the variance. Thus, the value of $K$ will be negative when the expected value of the terminal consumption is low or when uncertainty over terminal consumption, represented by the variance, is high. In this model, the sign of $K$ in the theoretical relationship between risk aversion and the interest rate is ambiguous, and therefore, an empirical issue. The Consumption CAPM with power utility gives the

Hypothesis III: The comparative static result (4.4), relating the change in yield and the yield level to the change in risk preferences, must hold. 
Using my measure of risk aversion I can test whether the data supports the postulated relationship. To do this, I test the statistical significance of the $K$ coefficient in a linear regression model.

One caveat. The hypotheses are based on an equilibrium analysis that assumes risk aversion of agents so the objective function in the utility optimization problem is concave. ${ }^{9}$ As reported, I find evidence of risk seeking in my sample. ${ }^{10}$ This finding should not be taken to imply that all agents are risk seeking. The changes in the measure of risk seeking should be taken as a proxy for changes in risk preferences in the society. It is the relationship between changes in risk preferences and changes in interest rates that is being tested.

\subsection{Risk Aversion and Bond Yields}

Asset pricing theories suggest that risk preferences should have an effect on the equilibrium interest rate. The exact functional form of the relationship between the interest rate and risk aversion depends on the specific equilibrium model. Having discussed how lottery bond prices can be used to extract information about risk preferences of market participants, I now investigate the effect of risk aversion on the yields of Russian government bonds.

First, consider the relationship between the interest rate and the coefficient of risk seeking determined from the changes in Russian lottery bond prices around the lottery dates. To control for serial correlation in yield series, lagged values of both the dependent and independent variable are included in the regression of log-yield on the estimated risk seeking coefficient, ${ }^{11}$

$$
\begin{aligned}
\ln \left(1+Y_{t}\right) & =\underset{(-0.51)}{-0.00142}+\underset{(15.61)}{1.00} \cdot \ln \left(1+Y_{t-1}\right)+\underset{(1.37)}{6.52} \cdot R S_{t}+\underset{(1.19)}{5.57} \cdot R S_{t-1} \\
R^{2} & =89.2 \%, \quad R_{a d j}^{2}=88.3 \%, \quad D W=1.86
\end{aligned}
$$

For all regressions, the numbers in parentheses are the $t$-statistics; Durbin-Watson (DW) statistic is also reported. The coefficients for the current and the lagged risk seeking estimate are not significant at conventional levels (the $p$-values are 0.179 and 0.241 ), but the positive value of the coefficient for $R S_{t}$ is encouraging since it is consistent with the postulated hypothesis of a positive relationship between risk preferences and interest rates.

\footnotetext{
${ }^{9}$ According to Duffie (1988) concavity of the utility of wealth function is not necessary for the CAPM.

${ }^{10}$ Jackwerth (2000) finds evidence of risk seeking in the U.S. post 1987 crash period.

${ }^{11}$ See Hamilton (1994) for the discussion of regressions with lagged dependent and independent variable.
} 
Next, the longer $R S I$ index time series is used to estimate the linear model in levels,

$$
\begin{aligned}
\ln \left(1+Y_{t}\right) & =\underset{(1.04)}{0.000984}+\underset{(42.51)}{0.966} \cdot \ln \left(1+Y_{t-1}\right)+\underset{(3.47)}{0.000344} \cdot R S I_{t}-\underset{(-3.09)}{0.000310} \cdot R S I_{t-1} \\
R^{2} & =95.3 \%, \quad R_{a d j}^{2}=95.1 \%, \quad D W=1.77
\end{aligned}
$$

Lagged values are included in the regression in order to control for serial correlation in the interest rate series. I find evidence of a positive relationship between risk preferences and risk-free rate which is consistent with the prediction of the CAPM and with Hypothesis I. This agrees with the economic intuition that high levels of risk seeking are associated with low demand for a safe asset, low bond prices, and hence, high yields. The estimated positive relationship between changes in risk seeking and changes in bond yield is equivalent to a positive relationship between changes in risk aversion and changes in risk-free bond prices.

Another approach for controlling serial correlation is to first-difference the data and estimate the relation

$$
\begin{aligned}
\Delta \ln \left(1+Y_{t}\right) & =\underset{(-0.76)}{-0.000066}+\underset{(3.51)}{0.000350 \cdot \Delta R S I_{t}} \\
R^{2} & =11.4 \%, \quad R_{a d j}^{2}=10.5 \%, \quad D W=1.72 \\
\Delta \ln \left(1+Y_{t}\right) & =\ln \left(1+Y_{t}\right)-\ln \left(1+Y_{t-1}\right) \\
\Delta R S I_{t} & =R S I_{t}-R S I_{t-1}
\end{aligned}
$$

The slope coefficient is significant at the 1\% level. Again, the regression indicates that an increase in the risk seeking measure corresponds to an increase in the riskless bond's yield. These results are consistent with Hypothesis I.

The result is also consistent with the notion of competition among government bonds. Increased appetite for risk results in increased demand for lottery bonds. Yields on other government securities must then increase.

To check robustness, six influential observations are removed and the last equation is reestimated. The slope coefficient remains positive and significant at the $1 \%$ level.

As another robustness check, I decompose the change in the market value of the future lotteries into the change in the expected lottery value and change in risk preferences. I estimate the following 
relationship,

$$
\begin{aligned}
\Delta \mathbb{M}_{t}[\text { Lotteries }] & =\underset{(0.68)}{0.84}+\underset{(2.08)}{6.58} \cdot \Delta \mathbb{E}_{t}[\text { Lotteries }]+\Delta \widehat{u}_{t} \\
R^{2} & =4.3 \%, \quad R_{a d j}^{2}=3.3 \%, \quad D W=1.96
\end{aligned}
$$

The slope coefficient is significant at the $5 \%$ level. The residuals, $\Delta \widehat{u}_{t}$, reflect changes in the market value of lotteries not caused by changes in the expected value of future lotteries, and correspond to the change in risk preferences. I now estimate

$$
\begin{aligned}
\Delta Y_{t} & =\underset{(-0.49)}{-0.000043}+\underset{(3.37)}{0.000024} \cdot \Delta \widehat{u}_{t} \\
R^{2} & =10.6 \%, \quad R_{a d j}^{2}=9.7 \%, \quad D W=1.73
\end{aligned}
$$

The slope coefficient is significant at the $1 \%$ level.

Having established a positive relationship between changes in risk seeking and changes in yields, I proceed to testing (4.3) directly. The following linear model is estimated

$$
\begin{aligned}
\Delta \ln \left(1+Y_{t}\right) & =\underset{(-1.40)}{-0.000115}+\underset{(4.40)}{0.00172} \cdot \Delta R S I_{t}-\underset{(-3.61)}{0.000134} \cdot R S I_{t-1} \cdot \Delta R S I_{t} \\
R^{2} & =22.1 \%, \quad R_{a d j}^{2}=20.4 \%, \quad D W=1.99
\end{aligned}
$$

The slope coefficients are significant at the $1 \%$ level. The coefficient on $\Delta R S I_{t}$ is positive, as was found in the previous tests and the coefficient on the product term, $R S I_{t-1} \cdot \Delta R S I_{t}$, is negative as predicted by the Consumption CAPM model. This result supports Hypothesis II. The model is also estimated with intercept set to zero. The result is

$$
\begin{aligned}
& \Delta \ln \left(1+Y_{t}\right)=\underset{(4.20)}{0.00162} \cdot \Delta R S I_{t}-\underset{(-3.41)}{0.000126} \cdot R S I_{t-1} \cdot \Delta R S I_{t} \\
& D W=1.94
\end{aligned}
$$

The slope coefficients are significant at $1 \%$ level.

I test Hypothesis III obtained from the Consumption CAPM with power utility of consumption by estimating the model

$$
\begin{aligned}
\frac{\Delta Y_{t}}{1+Y_{t-1}} & =\underset{(-0.76)}{-0.000065}+\underset{(3.51)}{0.000350 \cdot \Delta R S I_{t}} \\
R^{2} & =11.4 \%, \quad R_{a d j}^{2}=10.5 \%, \quad D W=1.72 \\
\Delta Y_{t} & =Y_{t}-Y_{t-1} .
\end{aligned}
$$


The slope coefficient is significant at the $1 \%$ level. As found in previous tests, the coefficient on $\Delta R S I_{t}$ is positive.

Time variation in the $R S I$ index is a proxy for changes in market risk preferences. I find strong evidence supporting the model's predictions when this proxy is used to test the theoretical relationship between changes in yields, and levels and changes in risk preferences. Three functional forms for the relationship between risk preferences and interest rates were tested, each derived from a different specification of the Consumption CAPM. All formulations share the same economic intuition: Low degree of risk aversion causes high equilibrium demand for the risky asset and low demand for the risk-free bond. The low demand results in a high risk-free rate.

\subsection{Causality Tests}

Classical tests for causality, as introduced by Granger (1969), are used to test whether changes in risk preferences cause changes in the interest rate. To test the null hypothesis that changes in risk preferences do not cause changes in the interest rate, I estimate two regressions,

$$
\begin{aligned}
\text { Unrestricted regression }: & \Delta Y_{t}=\beta_{0}+\beta_{1} \Delta Y_{t-1}+\beta_{2} \Delta R S I_{t-1}+\epsilon_{t} \\
\text { Restricted regression }: & \Delta Y_{t}=\beta_{0}+\beta_{1} \Delta Y_{t-1}+\epsilon_{t}
\end{aligned}
$$

The unrestricted regression is a regression of changes in the interest rate on the lagged changes in the interest rate and the lagged changes in the risk seeking index. The restricted regression is a regression of changes in the interest rate on the lagged changes in the interest rate. In the restricted regression, the coefficient for the changes in the risk seeking index is restricted to zero. The $F$ statistic is 7.34 and I reject the null hypothesis that $\beta_{2}=0$ ( $p$ value is 0.008$)$. I conclude that changes in risk preferences, captured by changes in the index, cause changes in the interest rate.

To test the null hypothesis that changes in the interest rate do not cause changes in the measure of risk preferences, the $R S I$ index, estimate two regressions,

$$
\begin{aligned}
\text { Unrestricted regression }: & \Delta R S I_{t}=\beta_{0}+\beta_{1} \Delta R S I_{t-1}+\beta_{2} \Delta Y_{t-1}+\epsilon_{t} \\
\text { Restricted regression }: & \Delta R S I_{t}=\beta_{0}+\beta_{1} \Delta R S I_{t-1}+\epsilon_{t}
\end{aligned}
$$

The unrestricted regression is a regression of changes in the risk seeking index on the lagged changes in the index and lagged changes in the interest rate. The restricted regression is a regression of 
changes in the risk seeking index on the lagged changes in the index only. The $F$ statistic for the test $\beta_{2}=0$ equals 0.0039 ( $p$ value is 0.95 ) and we cannot reject the null. I conclude that changes in interest rates do not cause changes in the $R S I$ index, the metric used for investor risk preferences.

\section{Discussion and Conclusion}

This paper presents the results of a study that uses market prices of lottery bonds to estimate a time series of the Arrow-Pratt measure of absolute risk aversion of market participants. It is found that over the time span of 16 years the buyers of lottery bonds pay prices consistent with risk seeking behavior. This is in contrast with surveys that find evidence of self-reported risk aversion. Other researchers studied Swedish and Danish lottery bonds but focused on different aspects of price behavior - such as tax issues. Still, a careful reading of their papers reveals evidence consistent with findings of this study.

Green and Rydqvist (1997) use Swedish government lottery bonds to study pricing of idiosyncratic risk and find that despite its idiosyncratic nature, prices appear to reflect aversion to this risk. For one of the bonds in the sample, however, the authors report a premium paid for holding diversifiable risk. ${ }^{12}$ When analyzing differences in prices, Green and Rydqvist (1997) postulate that violations of concavity of the investors' utility function may be in evidence in their sample. They interpret some findings as "direct evidence that some investors either value the skewness from the lotteries from individual bonds, which is reduced by diversification, or face wealth-related liquidity constraints, which limit their participation in the market through sequences." They also report evidence that, in some cases, the marginal investor values the lottery risk. Given the pricing in the Swedish lottery bond market, the authors conclude that "it is possible that investors are averse to the lottery risk associated with the smaller payment levels, yet still value the chance at very high payoffs. This, in turn, might suggest guaranteeing the lowest coupon level for all bonds." That is precisely what Russian government did in the 19th century. All coupons are distributed via lottery for Swedish bonds, so it is possible to receive no payment. Russian bonds guaranteed $5 \%$ annual coupon, in addition to the lottery feature. Studying Russian lottery bonds, I am able to focus on

\footnotetext{
${ }^{12}$ In a different study, Green and Rydqvist (1999) investigate the ex-day behavior of Swedish lottery bonds. Consistent with tax-based explanations, they find that price falls by more than the distribution when the bond reaches the ex-distribution day.
} 
the preferences toward high payoffs in the spirit of Friedman and Savage (1948).

Florentsen and Rydqvist (2002) study Danish lottery bonds which are Danish Treasury obligations and make coupon payments by lottery. Most bonds receive no payment, while a few winning bonds receive prizes up to 10,000 times the face value. The focus of the study is on the behavior of ex-day returns. Consistent with the costly arbitrage model of Kalay (1982) and Boyd and Jagannathan (1994), they find that the marginal valuation of the dividend is one-for-one, but that prices on average fall by more than the amount of the dividend. They conclude that abnormal ex-day returns reflect the cost of arbitrage.

A close look at Danish lottery bond prices reveals a pattern consistent with the behavior found in the Russian lottery bond market which is free from the tax complications. Florentsen and Rydqvist (2002) present a plot of the current yield for lottery bonds from 1976 to 1999 and compare it to the yield on regular Treasury bonds (Figure 3 in their paper). The plot shows that lottery bond yields are substantially lower than regular Treasury yields most of the time. The difference is substantial, often above five percentage points and frequently reaching six percentage points. In the late 1980s, the current yield on lottery bonds equalled approximately $3 \%$, while the Treasury yield stood at $9 \%$. They also report that lottery bonds were selling at an average price of $250 \%$ of par. Another plot in the paper shows the time-series of the yield to maturity for bonds issued in 1977 (Figure 4 in their paper). From it, one can see that a 1977 bond was traded at negative yields to maturity during the time period 1998-1999. Florentsen and Rydqvist (2002) point out that the model developed by Green and Rydqvist (1999) to explain negative yields to maturity in the Swedish lottery bond market based on tax arbitrage does not apply to the Danish market because the marginal tax rate is zero. Florentsen and Rydqvist (2002) therefore call negative yields to maturity in the Danish lottery bond market "a puzzle which we leave for future research." In light of the evidence from Russian lottery bond prices, behavior of Danish lottery bond prices is consistent with investors exhibiting preference towards the lottery and bidding up the prices until the bonds have negative yields to maturity. Perhaps another look at the Danish data is warranted.

I also find that the degree of risk seeking among market participants varies over time. I construct an index based on lottery bond prices and use it as a proxy for market risk preferences. The index makes it possible to test the effects of changes in risk preferences on asset prices. In such tests, the time variation in the investor risk aversion index is compared to the dynamics of the Russian bond 
market over the period 1889 to 1904. I find evidence of a positive relationship between changes in risk aversion and changes in prices of risk-free bonds. This result is in accord with economic intuition that high risk aversion is associated with high demand for a safe asset and hence, high equilibrium bond prices and low interest rates. I also test implications of the Consumption CAPM to determine how changes in the risk free rate are related to changes and levels of risk aversion. I find evidence supporting the Consumption CAPM. Finally, the Granger causality test indicates that changes in risk preferences, captured by changes in the index, cause changes in the risk-free rate. The paper thus provides evidence on the role of risk aversion in securities market dynamics. 


\section{A Appendix. 1866 Lottery Bonds: Summary of Contractual Fea- tures}

- Bond face value: 100 rubles.

- Principal Repayment: The bonds were recalled through random recall drawings during a 60year period. Recall drawings took place on March 1 and September 1 of every year. The first recall drawing was on September 1, 1866 and the last recall drawing was scheduled on March 1, 1926. The bonds were recalled in series. The number of bonds recalled at each recall drawing was stated in the schedule of drawings printed on the back of each bond certificate.

- When a bond was recalled the owner received an amount exceeding the face value. The amount paid depended on the drawing and grew over time from 120 to 150 rubles. Table A1 provides a summary of recall payments. The cash payment on retired bonds was made three months after the date of the recall drawing.

\begin{tabular}{|c|c|c|}
\hline \multicolumn{3}{|c|}{ Table A1 } \\
\hline Recall Payment (rubles) & Total Number of Bonds & Effective Dates \\
\hline 120 & 45,100 & 1 Sep 1866 - 1 Mar 1876 \\
\hline 125 & 108,500 & 1 Sep 1876 - 1 Mar 1891 \\
\hline 130 & 137,800 & 1 Sep 1891 - 1 Mar 1901 \\
\hline 135 & 222,200 & 1 Sep 1901 - 1 Mar 1911 \\
\hline 140 & 140,100 & 1 Sep 1911 - 1 Mar 1916 \\
\hline 145 & 196,500 & 1 Sep 1916 - 1 Mar 1922 \\
\hline 150 & 149,800 & 1 Sep 1922 - 1 Mar 1926 \\
\hline
\end{tabular}

- Once a bond was recalled, it no longer earned interest. However, the bonds recalled at the first drawing received the annual coupon payment at the same time as they receive the recall payment.

- The prize drawings and recall drawings took place on the same date. On the day of the drawings, the prize drawing took place before the recall drawing. Both drawings were first 
conducted on September 1, 1866. According to the lottery schedule printed on the back of every bond certificate, prize drawings took place twice a year during the first 30 years and once a year during the last 30 years.

\begin{tabular}{ll}
\hline \hline & \multicolumn{1}{c}{ Table A2 } \\
$\mathbf{1 8 6 6}$ Lottery & Bonds: Prizes Awarded at Each Lottery Drawing \\
\hline Prize Value, $Z_{k}$ & Number of Prizes \\
\hline 200,000 rubles & 1 prize \\
75,000 rubles & 1 prize \\
40,000 rubles & 1 prize \\
25,000 rubles & 1 prize \\
10,000 rubles & 3 prizes \\
8,000 rubles & 5 prizes \\
5,000 rubles & 8 prizes \\
1,000 rubles & 20 prizes \\
500 rubles & 260 prizes \\
\hline \hline
\end{tabular}

- Prizes were awarded to individual bonds. In a prize drawing, a serial number was drawn from one drum and an individual bond number was drawn from a different drum. Both numbers together identified the individual bond. After the winner for a prize was announced, the numbers were returned into the drums. However, on any given date a bond could win only one prize.

- The prizes were paid in a lump sum payment three months after the drawing date. A winning bond remained the property of its owner allowing the owner to participate in all future lottery drawings until the bond was recalled.

\section{B Appendix}

The expression for the conditional probability of recall is derived in this appendix. The probability $\mu_{t}^{i}=\mathbb{P}\{$ Recall on drawing $i \mid$ Outstanding at $t\}$ is the probability of recall at the $i$-th recall drawing conditional on not being recalled at any of the drawings that took place prior to time $t$. 
At a recall drawing $i, n_{i}$ bonds are recalled. All numbers $n_{i}$ are known from the table printed on the bond certificate. There were 1,000,000 bonds originally issued. Therefore, $O_{i}$, the number of bonds outstanding at the time of the $i$-th drawing,

$$
O_{i}=1,000,000-\sum_{j=1}^{i-1} n_{j}
$$

If $i=1$ the sum equals zero.

Let $i_{1}$ be an integer in the interval $[1,120]$ equal to the number of the next drawing in which the bond will participate (the first drawing at or after time $t$ ). At this drawing $n_{i_{1}}$ bonds will be recalled from $O_{i_{1}}$ outstanding bonds. Therefore:

$$
\mu_{t}^{i_{1}}=\frac{n_{i_{1}}}{O_{i_{1}}}
$$

For a bond to be recalled at the next drawing after the drawing $i_{1}$, the bond must not be recalled at $i_{1}$ (event that occurs with probability $1-n_{i_{1}} / O_{i_{1}}$ ) and the bond must be recalled at this next drawing, $i_{1}+1$. Therefore:

$$
\mu_{t}^{i_{1}+1}=\left[1-\frac{n_{i_{1}}}{O_{i_{1}}}\right] \cdot \frac{n_{i_{1}+1}}{O_{i_{1}+1}}
$$

Applying this argument by induction, for any $i>i_{1}$, we obtain:

$$
\mu_{t}^{i}=\frac{n_{i}}{O_{i}} \cdot \prod_{j=i_{1}}^{i-1}\left[1-\frac{n_{j}}{O_{j}}\right]
$$

and therefore:

$$
\mu_{t}^{i}= \begin{cases}0 & \text { if drawing } i \text { takes place before time } t \\ \frac{n_{i_{1}}}{O_{i_{1}}} & \text { for the first drawing after } t: i=i_{1} \\ \frac{n_{i}}{O_{i}} \cdot \prod_{j=i_{1}}^{i-1}\left[1-\frac{n_{j}}{O_{j}}\right] & \text { for all other } i\end{cases}
$$

It is comforting to know that these probabilities add up to unity, as established below.

\section{Proposition B.1 (Recall probabilities)}

$$
\sum_{i=1}^{120} \mu_{t}^{i}=1, \quad \forall t .
$$


Proof. We want to prove: $\sum_{i=1}^{120} \mu_{t}^{i}=1$. By definition, $O_{i}=1,000,000-\sum_{j=1}^{i-1} n_{j}$ and hence, $O_{i+1}=1,000,000-\sum_{j=1}^{i} n_{j}=1,000,000-\sum_{j=1}^{i-1} n_{j}-n_{i}=O_{i}-n_{i}$. Hence, $O_{i+1}=O_{i}-n_{i}$.

The integer $i_{1}$, the first drawing at which the bond might be recalled, is known at time $t$. Write

$$
\sum_{i=1}^{120} \mu_{t}^{i}=\sum_{j=1}^{i_{1}-1} 0+\frac{n_{i_{1}}}{O_{i_{1}}}+\sum_{j=i_{1}+1}^{120} \frac{n_{j}}{O_{j}} \prod_{k=i_{1}}^{j-1}\left[1-\frac{n_{k}}{O_{k}}\right]
$$

Now consider the product

$$
\begin{aligned}
\prod_{k=i_{1}}^{j-1}\left[1-\frac{n_{k}}{O_{k}}\right] & =\frac{O_{i_{1}}-n_{i_{1}}}{O_{i_{1}}} \times \frac{O_{i_{1}+1}-n_{i_{1}+1}}{O_{i_{1}+1}} \times \ldots \times \frac{O_{j-2}-n_{j-2}}{O_{j-2}} \times \frac{O_{j-1}-n_{j-1}}{O_{j-1}} \\
& =\frac{O_{i_{1}+1}}{O_{i_{1}}} \times \frac{O_{i_{1}+2}}{O_{i_{1}+1}} \times \ldots \times \frac{O_{j-1}}{O_{j-2}} \times \frac{O_{j}}{O_{j-1}} \\
& =\frac{O_{j}}{O_{i_{1}}}
\end{aligned}
$$

where the second equality follows from $O_{i+1}=O_{i}-n_{i}$. Then

$$
\sum_{i=1}^{120} \mu_{t}^{i}=\frac{n_{i_{1}}}{O_{i_{1}}}+\sum_{j=i_{1}+1}^{120} \frac{n_{j}}{O_{j}} \frac{O_{j}}{O_{i_{1}}}=\frac{n_{i_{1}}}{O_{i_{1}}}+\frac{1}{O_{i_{1}}} \sum_{j=i_{1}+1}^{120} n_{j}=\frac{1}{O_{i_{1}}} \sum_{j=i_{1}}^{120} n_{j} .
$$

Recall that $O_{i_{1}}$ is the number of bonds outstanding at the time of the drawing $i_{1}$. During the drawings $i_{1}$ through 120 all outstanding bonds, $O_{i_{1}}$, must be recalled:

$$
\sum_{j=i_{1}}^{120} n_{j}=O_{i_{1}} \Rightarrow \sum_{i=1}^{120} \mu_{t}^{i}=1
$$




\section{References}

[1] Aït-Sahalia, Y., and A. W. Lo, 2000, Nonparametric Risk Management and Implied Risk Aversion, Journal of Econometrics 94, 9-51.

[2] Arrow, K., 1964, The Role of Securities in the Optimal Allocation of Risk-Bearing, The Review of Economic Studies 31, 91-96.

[3] Arrow, K., 1965, The Theory of Risk Aversion, Lecture 2 in Aspects of the Theory of RiskBearing (Yrjo Jahnsson Lectures), Yrjo Jahnssonin Saatio, Helsinki.

[4] Arrow, K., 1970, Essays in the Theory of Risk-Bearing (Amsterdam: North-Holland.).

[5] Barberis, Nicholas, and Ming Huang, 2001, Mental Accounting, Loss Aversion, and Individual Stock Returns, Journal of Finance 56, 1247-1295.

[6] Barberis, Nicholas, Ming Huang, and Tano Santos, 2001, Prospect Theory and Asset Prices, Quarterly Journal of Economics 116, 1-53.

[7] Bernoulli, Daniel, 1738, "Specimen Theoriae Novae de Mensura Sortis," Commentarii Academiae Scientiarum Imperialis Petropolitanae, Tomus V [Papers of the Imperial Academy of Sciences in Petersburg, Vol. V], pp. 175-192, English translation by Dr. Louise Sommer published as "Exposition of a New Theory on the Measurement of Risk," in Econometrica 22, Jan. 1954, 23-36.

[8] Boyd, J., and Jagannathan, R., 1994, Ex-dividend price behavior of common stocks: Fitting some pieces of the puzzle, Review of Financial Studies 7, 711-741.

[9] Brav, Alon, George M. Constantinides, Christopher C. Geczy, 2002, Asset Pricing with Heterogeneous Consumers and Limited Participation: Empirical Evidence, Journal of Political Economy 110, 793-824.

[10] Breeden, Douglas T., 1979, An intertemporal capital asset pricing model with stochastic consumption and investment opportunities, Journal of Financial Economics 7, 265-296.

[11] Breeden, Douglas T., 1986, Consumption, production, inflation, and interest rates: A synthesis, Journal of Financial Economics 16, 3-39. 
[12] Chan, Yeung Lewis, Leonid Kogan, 2002, Catching Up with the Joneses: Heterogeneous Preferences and the Dynamics of Asset Prices, Journal of Political Economy 110, 1255-1285.

[13] Duffie, D., Security Markets Stochastic Models, Academic Press, San Diego, CA, 1988.

[14] Florentsen B, Rydqvist K., 2002, Ex-day behavior when investors and professional traders assume reverse roles: The case of Danish lottery bonds, Journal of Financial Intermediation $11,152-175$.

[15] Friend, Irwin, and Marshall E. Blume, 1975, The Demand for Risky Assets, American Economic Review 65, 900-922.

[16] Granger, C. W. J., 1969, Investigating Causal Relations by Econometric Models and CrossSpectral Methods, Econometrica 37, 424-438.

[17] Green, Richard C., Kristian Rydqvist, 1997, The Valuation of Non-Systematic Risks and the Pricing of Swedish Lottery Bonds, Review of Financial Studies 10, 447-480.

[18] Green, Richard C., Kristian Rydqvist, 1999, Ex-day behavior with dividend preference and limitations to short-term arbitrage: the case of Swedish lottery bonds, Journal of Financial Economics 53, 145-187.

[19] Grossman S. and Robert Shiller, 1982, Consumption correlatedness and risk measurement in economies with non-traded assets and heterogenous information, Journal of Financial Economics 51, 1379-1403.

[20] Guiso, Luigi and Monica Paiella, 2001, Risk Aversion, Wealth and Background Risk, CEPR Discussion Paper No. 2728.

[21] Hamilton, James D., 1994, Time Series Analysis (Princeton University Press, Princeton, NJ.).

[22] Hansen, Lars Peter, Kenneth J. Singleton, 1983, Stochastic Consumption, Risk Aversion, and the Temporal Behavior of Asset Returns, Journal of Political Economy 91, 249-265.

[23] Holt, Charles A., Susan K. Laury, 2002, Risk Aversion and Incentive Effects, American Economic Review 92, 1644-1655. 
[24] Jackwerth, Jens Carsten, 2000, Recovering Risk Aversion from Option Prices and Realized Returns, The Review of Financial Studies 13, 433-451.

[25] Kachelmeier, Steven J. and Mohamed Shehata, 1992, Examining Risk Preferences Under High Monetary Incentives: Experimental Evidence from the People's Republic of China, American Economic Review 82, 1120-1141.

[26] Kalay, A., 1982, The ex-dividend day behavior of stock prices: A re-examination of the clientele effect, Journal of Finance 37, 1059-1070.

[27] Lintner, John., 1965, The Valuation of Risk Assets and the Selection of Risky Investments in Stock Portfolios and Capital Budgets, Review of Economics and Statistics 47, 13-37.

[28] Lintner, John., 1970, The Market Price of Risk, Size of Market and Investor's Risk Aversion, Review of Economics and Statistics 52, 96-99.

[29] Lucas, Robert E., Jr., 1978, Asset Prices in an Exchange Economy, Econometrica 46, 14291445.

[30] Mankiw, N. Gregory, Stephen P. Zeldes, 1991, The consumption of stockholders and nonstockholders, Journal of Financial Economics 29, 97-112.

[31] Merton, Robert C., 1973, An intertemporal capital asset pricing model, Econometrica 41, $867-887$.

[32] Mossin, Jan, 1966, Equilibrium in a Capital Asset Market, Econometrica 34, 261-76.

[33] Novosti i Birzhevaya Gazeta. Various issues. (Yale SML: Film An N865).

[34] Pratt, J., 1964, Risk Aversion in the Small and in the Large, Econometrica 32,122-136.

[35] Schilbred, Cornelius, 1973, The Market Price of Risk, The Review of Economic Studies 40, 283-292.

[36] Sharpe, William F., 1964, Capital Asset Prices: A Theory of Market Equilibrium under Conditions of Risk, Journal of Finance 19, 425-42. 
[37] Shefrin, Hersh and Meir Statman, 2000, Behavioral Portfolio Theory, Journal of Financial and Quantitative Analysis 35, 127-151.

[38] Tarankov, 1992, Tsennye Bumagi Gosudarstva Rossiskogo, Moscow.

[39] Ukhov, Andrey D., 2002, Financial Innovation and Russian Government Debt Prior to 1918, Working paper, Yale School of Management.

[40] Vagner, A., 1871, Russkie Bunazhnye Den'gi, Kiev.. 
Figure 1

Estimated Risk Seeking Coefficient

From Price Changes of 1864 and 1866 Lottery Bonds

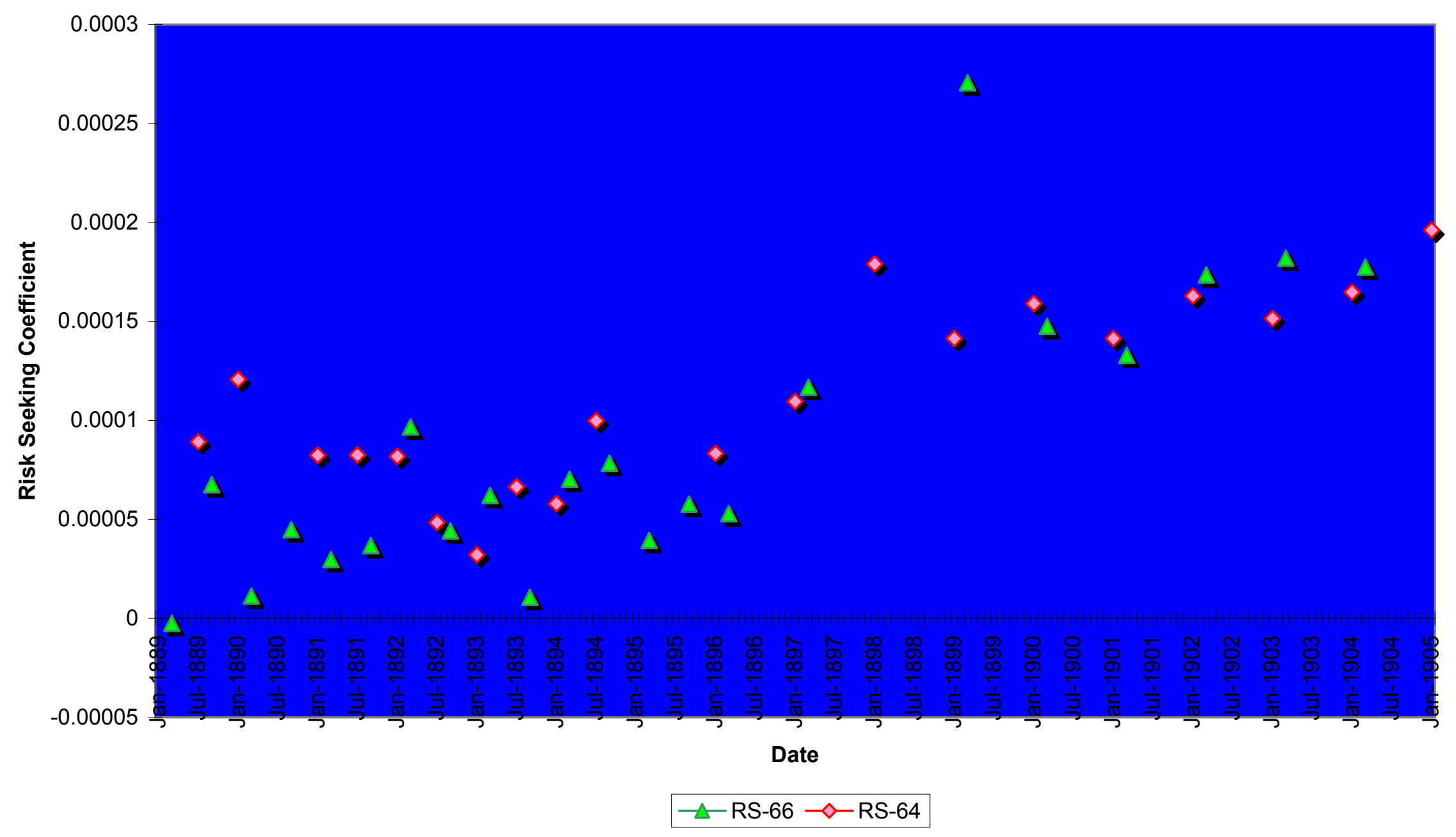


Figure 2

Risk Seeking Index and Estimated Risk Seeking Coefficient

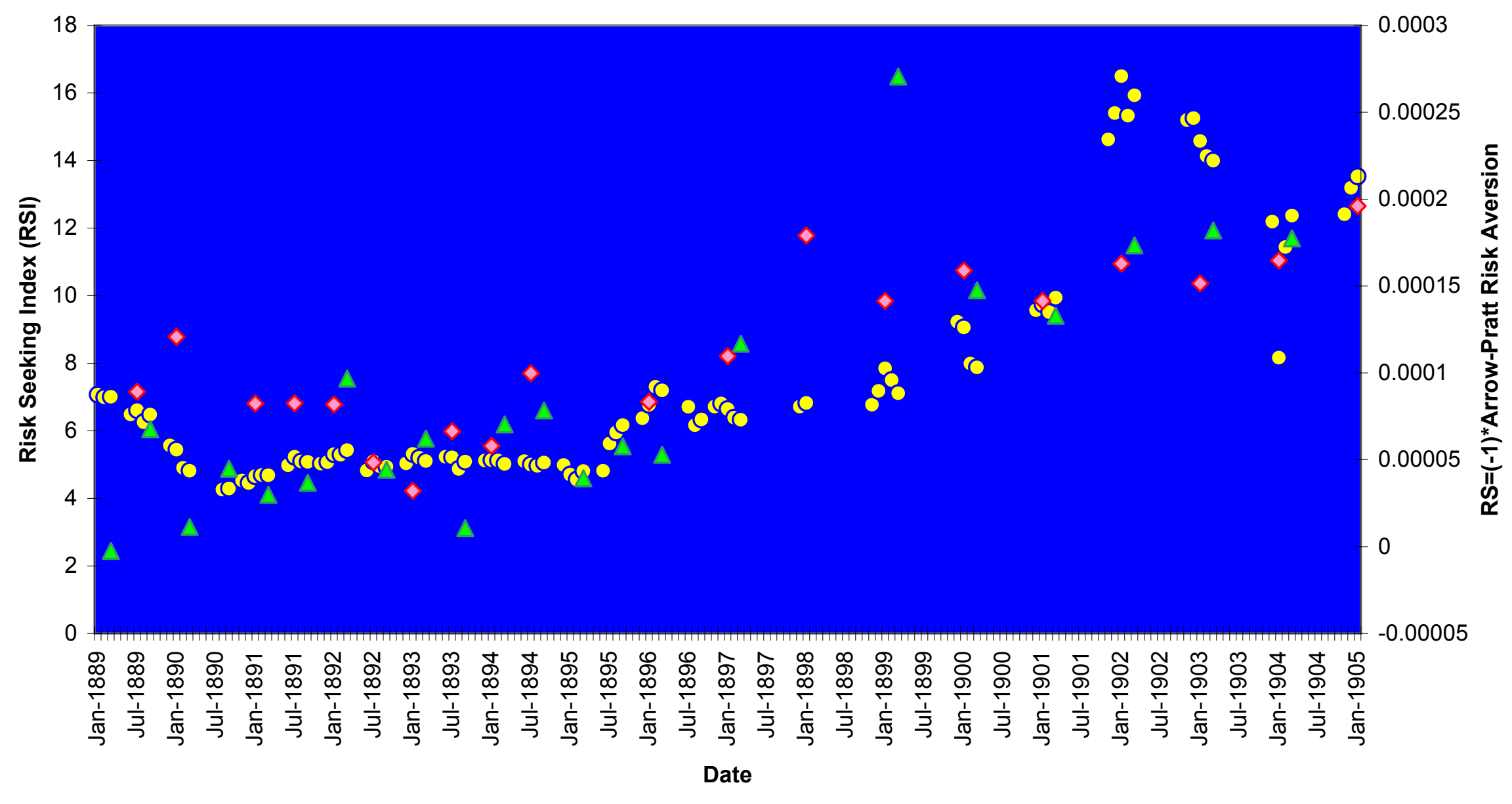

